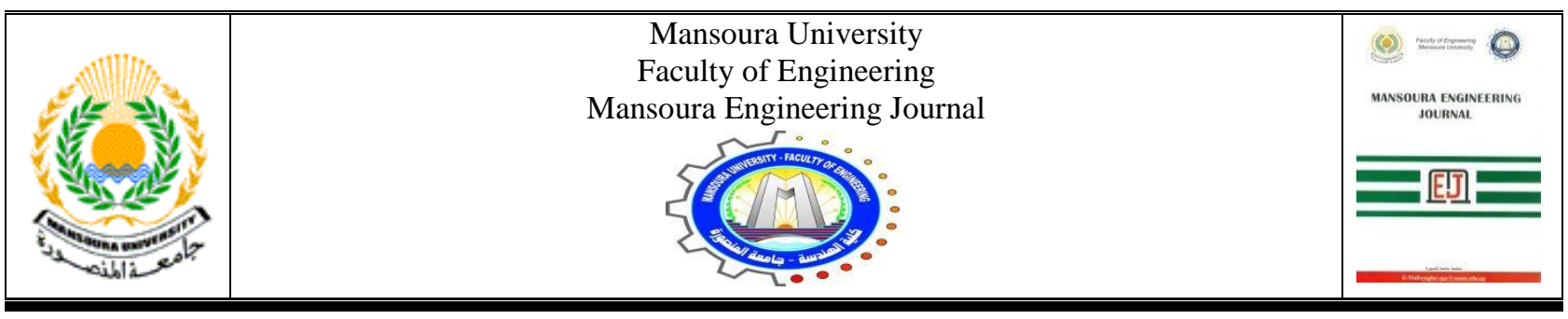

\title{
Effect of Tool Geometry, Feed Rate, and Rotational Speed of Thermal Friction Drilling Process on AISI 304 Stainless Steel

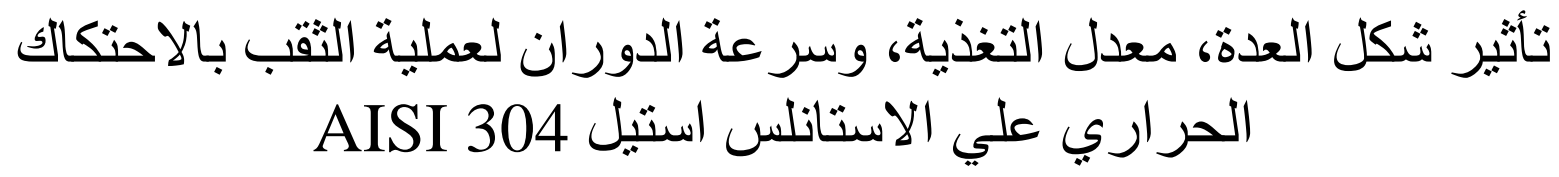

Sara A. El-Bahloul*, Hazem E. El-Shourbagy**, and Tawfik T. El-Midany***

*Asst. Lect. (Prod. Eng.), **Lect. (Prod. Eng.), and ***Prof. (Prod. Eng.)

Prod. \& Mech. Design Eng. Dept., Faculty of Engineering, Mansoura University, Egypt

*E-mail: elbahloul.sara@gmail.com, Tel.: +201007742266

\begin{abstract}
KEYWORDS
Thermal friction drilling;

Process parameters;

Fuzzy Logic; Bushing

length; Dimensional error; Roundness error; Axial force; Radial force
\end{abstract}

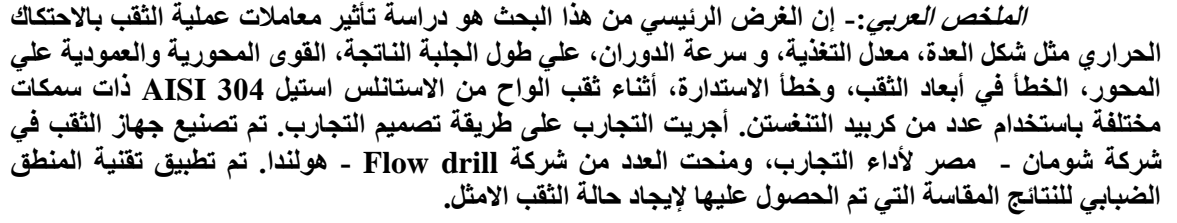

Abstract: - The main purpose of this research paper is to study experimentally the effects of the thermal friction drilling process parameters such as the tool geometry, feed rate, and rotational speed, on the resultant bushing length, axial and radial forces, hole dimensional error, and roundness error, while drilling AISI 304 stainless steel sheets with different thicknesses using tungsten carbide tools. The experiments were conducted based on the design of experiments method. A test rig was manufactured at Showman Company - Egypt to perform the experimental work, and the tools were offered by Flow drill Company Netherlands. Also Fuzzy Logic technique is applied to the obtained results to find the optimal drilling condition.

\section{INTRODUCTION}

$\mathrm{T}$ The product increasing of automobile industry, development of mechanical products, materials, or design of joining, force the producers to utilize new technologies [1,2]. Friction drilling, thermal drilling, form drilling, flow drilling, or friction stir drilling is a nontraditional hole-making method that uses the heat generated from friction between a rotating conical tool and the work piece to soften and penetrate the work material and generate a hole $[3,4]$.

Friction drilling compared to other methods of making holes and joining, no coolant is needed, which makes friction drilling a totally clean and environment friendly process. Also friction drilling is the best solution for joining sheet materials in simple, efficient and most economical way. The generated bush can be threaded with providing high strength load bearing surface due to more solid connection for attachment [4-9].

Since 1983, non-traditional hole-making methods were investigated [1-13]. Several authors studied the thermal friction drilling. Streppel A.H. and Kals H.J.J. [6], investigate the effect of tool diameter, workpiece thickness and material on the resulted feed force, contact temperature, and the driving moment. Miller S.F., Blau P.J., and Shih A.J. [9, 10] characterized the microstructural alterations and subsurface micro-indentation hardness changes on several materials as a result of the friction drilling process. Krasauskas $P$. [11] performed a statistical five variable linear regression analysis to evaluate the influence of plate thickness, rotational speed, feed rate, and materials mechanical properties, on the axial force and torque. Ozek C. and Demir Z. [12] investigated the effect of spindle speeds and feed rates in friction drilling of aluminum alloys, that is on the generated frictional heat, surface roughness, and bushing length.

The main purpose of the present work is to investigate experimentally and analytically using Fuzzy Logic technique the optimal parameters of thermal friction drilling process; namely, tool diameter $(d)$, friction angle $(\beta)$, friction contact area ratio (FCAR), feed rate (FR), and rotational speed (RS). AISI 304 stainless steel work material is employed with 1,2 , and $3 \mathrm{~mm}$ 
sheet metal thickness. The measured parameters are: bushing length (BL), axial force (AF), radial force (RF), hole dimensional error (DE), and roundness error (RE). Thus, the optimal performance could be ascertained to fit modern industrial requirements.

\section{TEST RIG AND EXPERIMENTAL SETUP}

Figure 1, shows the test rig, used in our previous work [13] that is designed to carry out the experimental work. The test rig is manufactured at Showman Company - Egypt, with rotational speed up to $4200 \mathrm{rpm}$, and feed rate up to $218.182 \mathrm{~mm} / \mathrm{min}$. Total of 18 thermal friction tools are used to perform all experiments. The tools are offered by Flow drill Company - Netherlands. They are made of uncoated tungsten carbide.
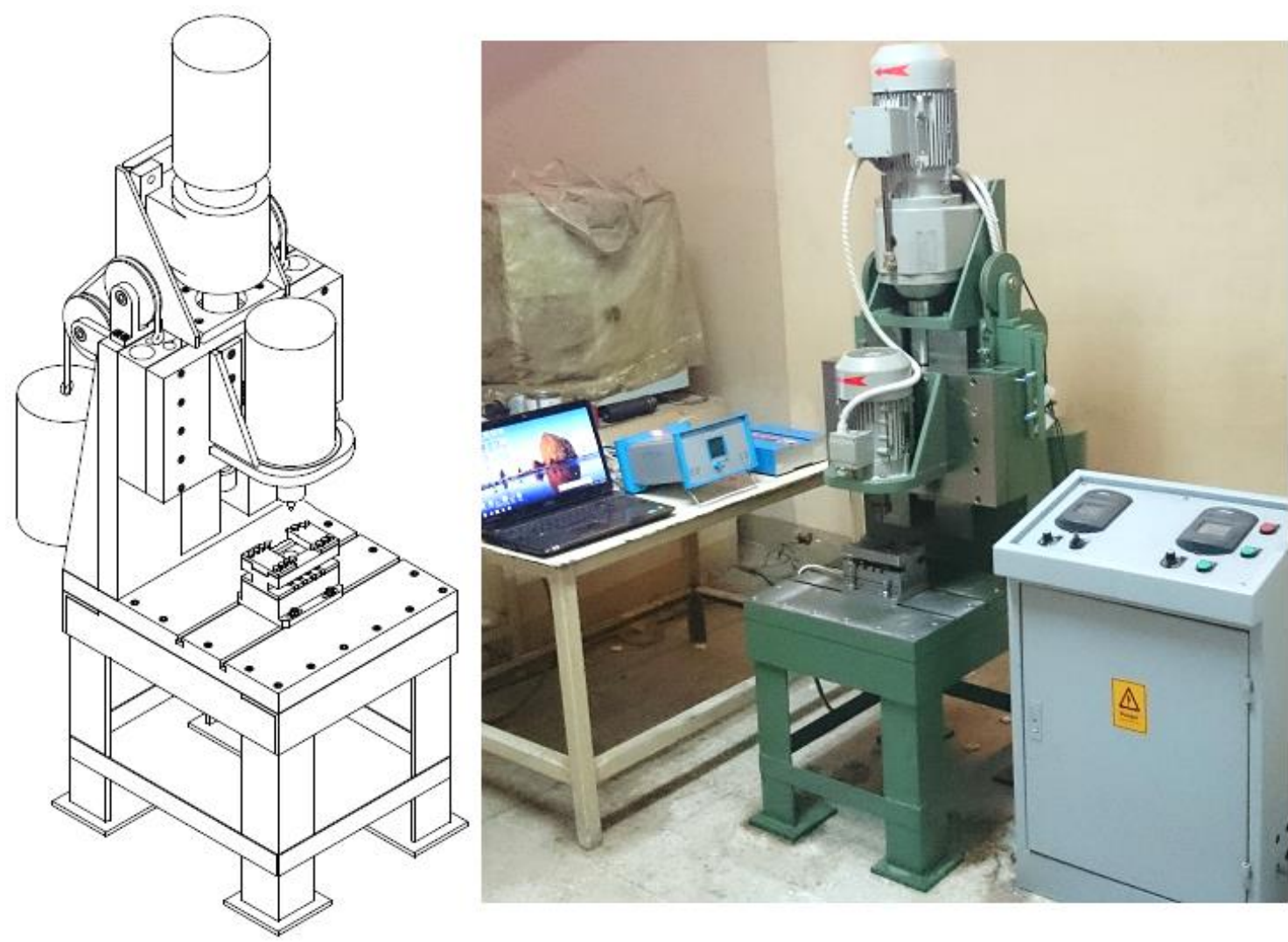

Fig. 1. The designed and manufactured test rig

An orthogonal array L18 [14] is applied to design the required experiments. Table 1, illustrates the investigated parameters and their values. Table 2, shows the obtained orthogonal array with 18 experiments' conditions, while each experiment was conducted three times. The orthogonal array is applied three times to work piece thickness $(t)$ of 1,2 , and $3 \mathrm{~mm}$, to study the effect of $t$ variation.
The resultant bushing length (BL) was measured by a micro Vernier. The hole dimensional error (DE) and roundness error (RE) were measured by a coordinate measuring machine (Status CMM). The axial force (AF) and radial force (RF) were measured by a multicomponent dynamometer (Kistler-Type 9257B).

Table 1. Process parameters and their levels

\begin{tabular}{c|c|c|c|c|c} 
Process Parameters & Symbol & Unit & Level 1 & Level 2 & Level 3 \\
\hline Tool diameter & $d$ & Mm & 5.4 & 7.3 & 9.2 \\
\hline Friction angle & $\beta$ & Degree & $30^{\circ}$ & $45^{\circ}$ & $60^{\circ}$ \\
\hline Friction contact area ratio & FCAR & - & $50 \%$ & $75 \%$ & $100 \%$ \\
\hline Rotational speed & RS & Rpm & 2500 & 3000 & 3500 \\
\hline Feed rate & FR & $\mathrm{mm} / \mathrm{min}$ & 60 & 100 & 140
\end{tabular}


Table 2. Five three-levels factors L18 orthogonal array

\begin{tabular}{c|c|c|c|c|c} 
Exp. No. & $\boldsymbol{d}(\mathrm{mm})$ & $\boldsymbol{b}($ degree $)$ & FCAR & FR $(\mathrm{mm} / \mathrm{min})$ & $\mathbf{R S}(\mathrm{rpm})$ \\
\hline 1 & 5.4 & 30 & 50 & 60 & 3000 \\
\hline 2 & 5.4 & 30 & 75 & 100 & 2500 \\
\hline 3 & 5.4 & 45 & 50 & 140 & 3500 \\
\hline 4 & 5.4 & 45 & 100 & 140 & 2500 \\
\hline 5 & 5.4 & 60 & 75 & 60 & 3500 \\
\hline 6 & 5.4 & 60 & 100 & 100 & 3000 \\
\hline 7 & 7.3 & 30 & 100 & 60 & 3500 \\
\hline 8 & 7.3 & 30 & 100 & 140 & 3000 \\
\hline 9 & 7.3 & 45 & 50 & 100 & 3500 \\
\hline 10 & 7.3 & 45 & 75 & 100 & 3000 \\
\hline 11 & 7.3 & 60 & 50 & 60 & 2500 \\
\hline 12 & 7.3 & 60 & 75 & 140 & 2500 \\
\hline 13 & 9.2 & 30 & 50 & 100 & 2500 \\
\hline 14 & 9.2 & 30 & 75 & 140 & 3500 \\
\hline 15 & 9.2 & 45 & 75 & 60 & 3000 \\
\hline 16 & 9.2 & 45 & 100 & 60 & 2500 \\
\hline 17 & 9.2 & 60 & 50 & 140 & 3000 \\
\hline 18 & 9.2 & 60 & 100 & 100 & 3500
\end{tabular}

\section{RESULTS AND DISCUSSION}

As mentioned above and illustrated in Table 2, each plotted point of the following results is the average of six experiments, each of them repeated three times. Figure 2, shows the effect of the tool operating parameters on the resultant BL. There is no pronounced effect of $\beta$, FCAR, FR, and RS, on the BL. Therefore, the tool with $\beta=30^{\circ}$ is recommended because its ability to higher penetration into work material. It has been reported that, the minimum bushing length to be threaded based on ISO 898, is calculated according to the following Equations (1 and 2) [15].
$L_{e}(\min )=\frac{2 A_{t}}{0.5 \pi(D-0.64952 p)}$

$A_{t}=\frac{\pi}{4}(D-0.938194 p)^{2}$

Where $L_{e}$ is the length of the thread engagement, $A_{t}$ is the screw thread tensile stress area, D is the basic diameter, and $p$ is the thread pitch. The minimum $\mathrm{L}_{\mathrm{e}}$ for M6, M8, and M10 threaded hole are 4.79, 6.48, and 8.18 $\mathrm{mm}$ respectively. Almost all the values of the $\mathrm{BL}$ produced lies within the permissible range according to the calculated $\mathrm{L}_{\mathrm{e}}$.

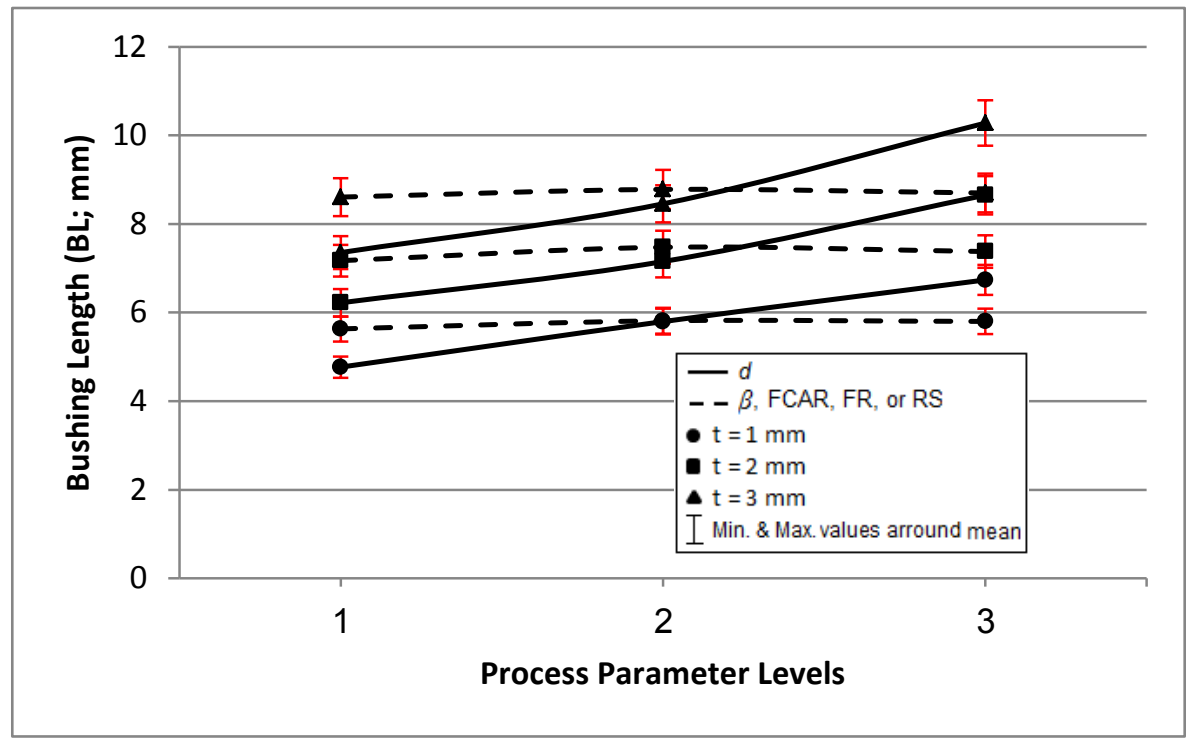

Fig. 2. Effect of the considered process parameters on the bushing length

Figures (3 to 7), show the effect of the tool operating parameters on the resultant forces. Generally, the values of the RF are very small compared to the AF. Figure 3, shows the effect of $d$ on the resultant forces. The lowest AF achieved at $d=7.3 \mathrm{~mm}$. However, for the material thickness under investigation, the AF varies with maximum of $20 \%$. Increasing $\beta$ increases the $\mathrm{AF}$, as shown in Fig. 4. Its effects are pronou nced with increasing $t$. For all material thickness under investigation, the lowest $\mathrm{AF}$ achieves at $\beta=30^{\circ}$. Increasing the FCAR increases the AF as shown in Fig. 5.
Therefore 50\% FCAR shows the lowest AF. Increasing the FR increases the AF as shown in Fig. 6. Its effect is pronounced with increasing $t$ to maximum percentage of $23 \%$ of the AF at $t=3 \mathrm{~mm}$. In general, FR of $60 \mathrm{~mm} / \mathrm{min}$ gives the lowest values of the resultant AF. It has been noticed in Fig. 7 that, increasing the RS decreased the resultant forces not more than $17 \%$, and by increasing $t$, the resultant $\mathrm{AF}$ will be increased by $52 \%$ when the material thickness is form $t=1 \sim 2 \mathrm{~mm}$, while it is $40 \%$ from $t=2 \sim 3 \mathrm{~mm}$, and $70 \%$ from $t=1 \sim 3 \mathrm{~mm}$. 


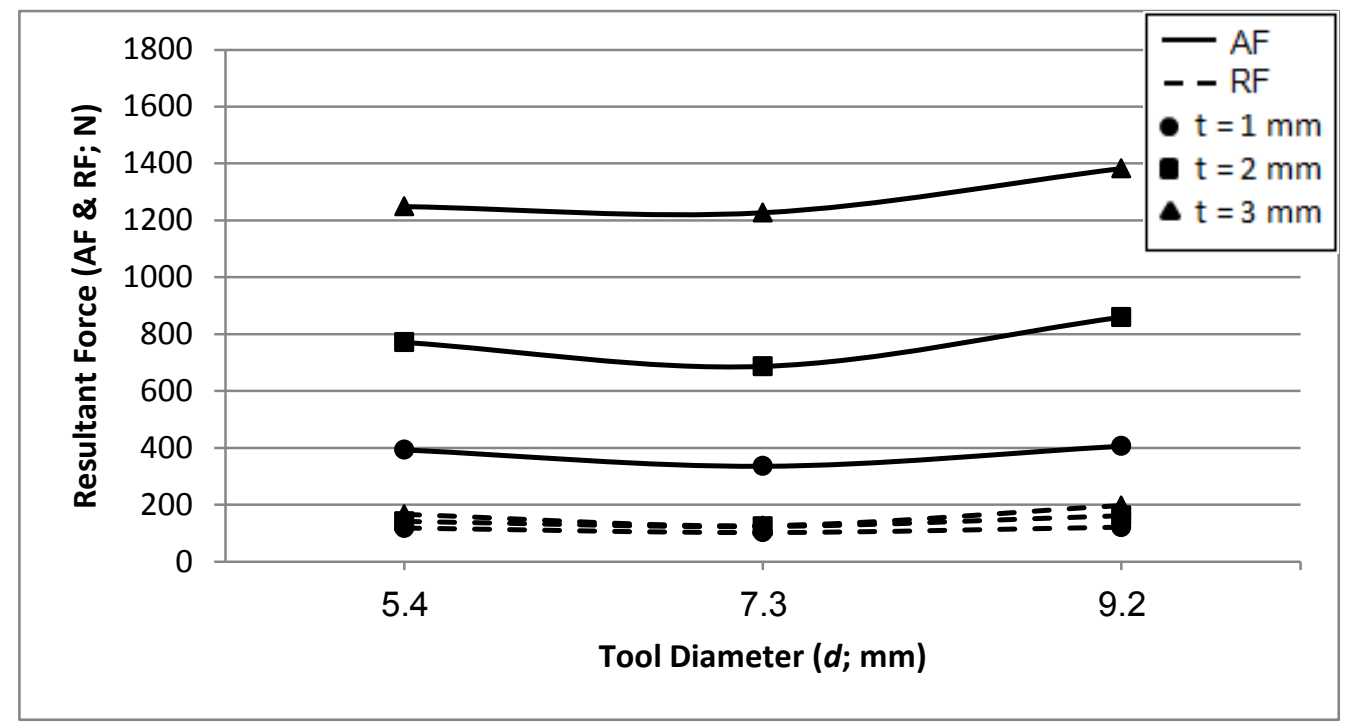

Fig. 3. Effect of tool diameter on the resultant force

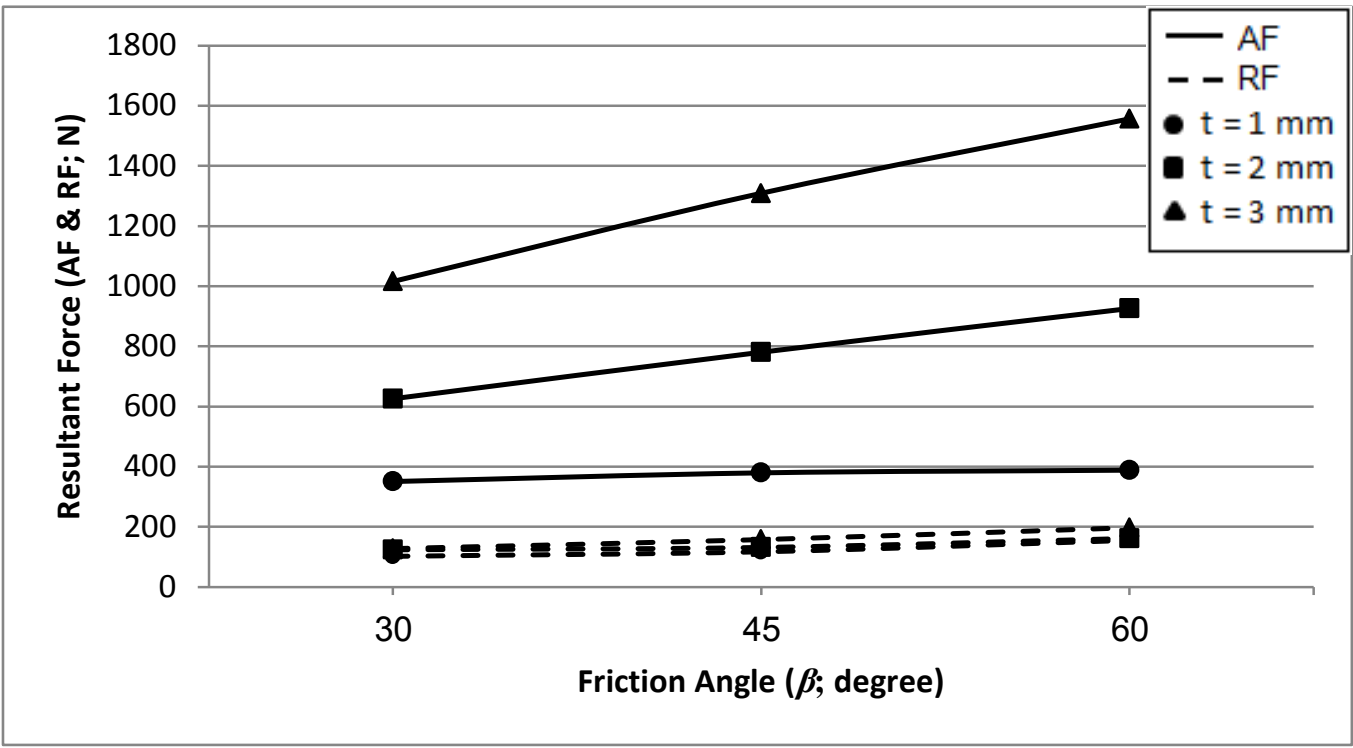

Fig. 4. Effect of friction angle on the resultant force

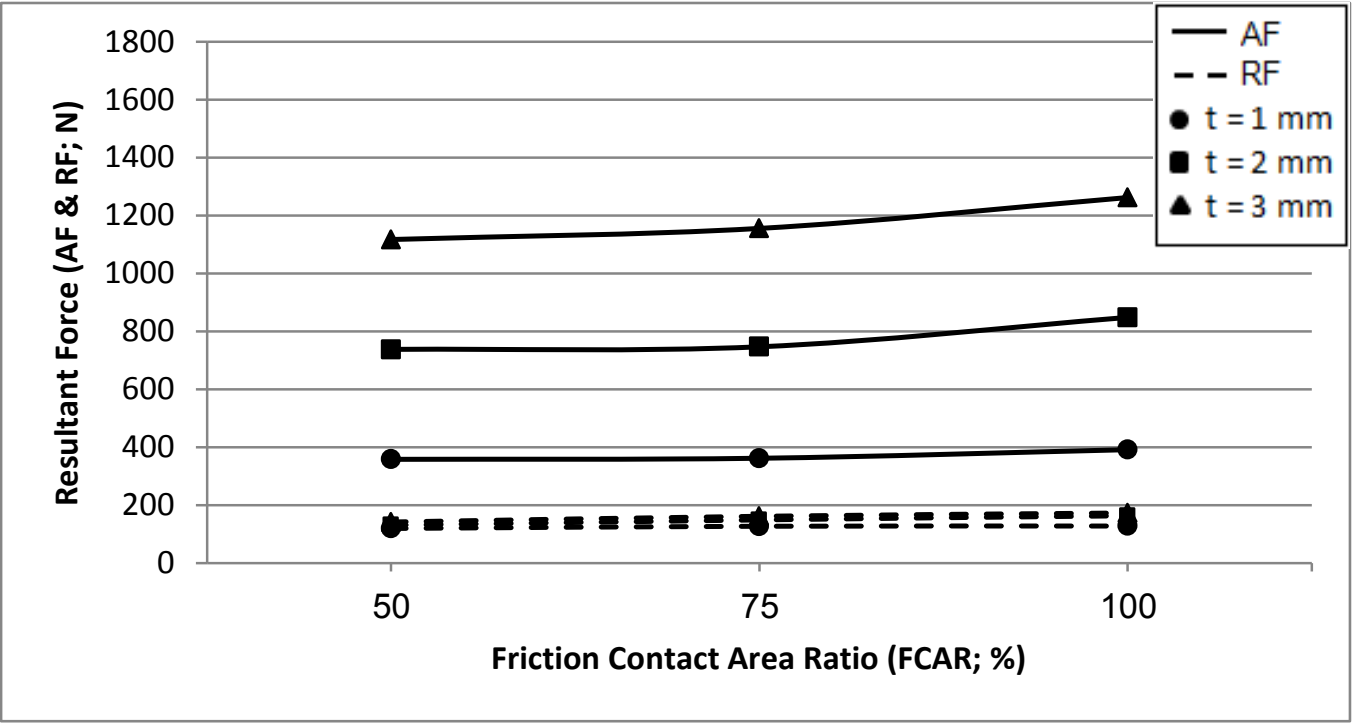

Fig. 5. Effect of friction contact area ratio on the resultant force 


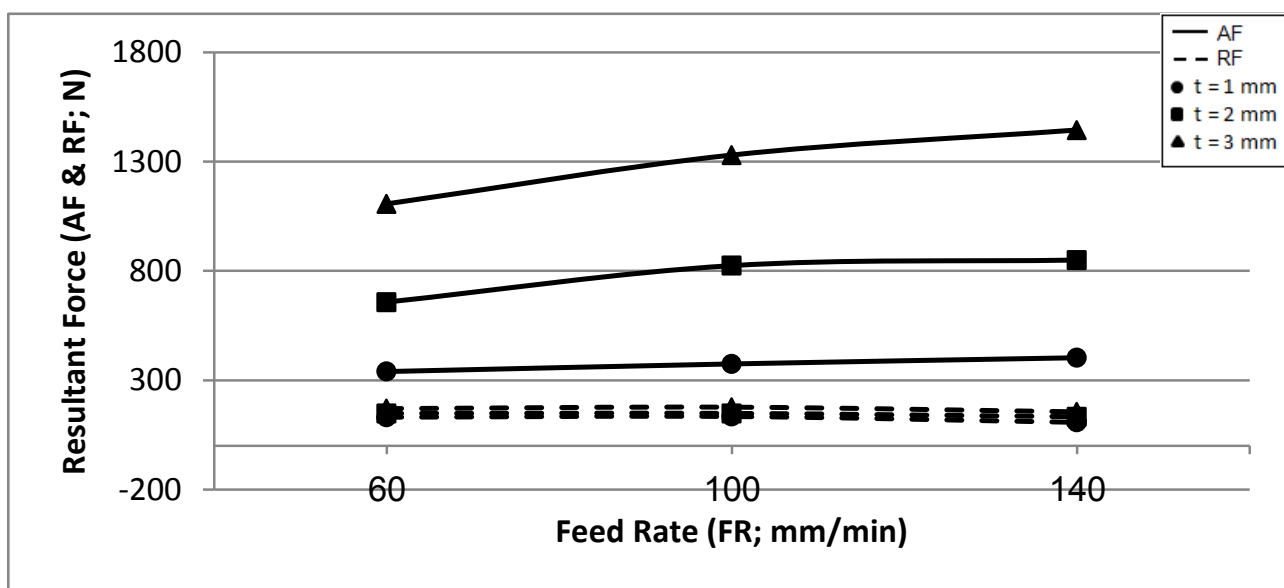

Fig. 6. Effect of feed rate on the resultant force

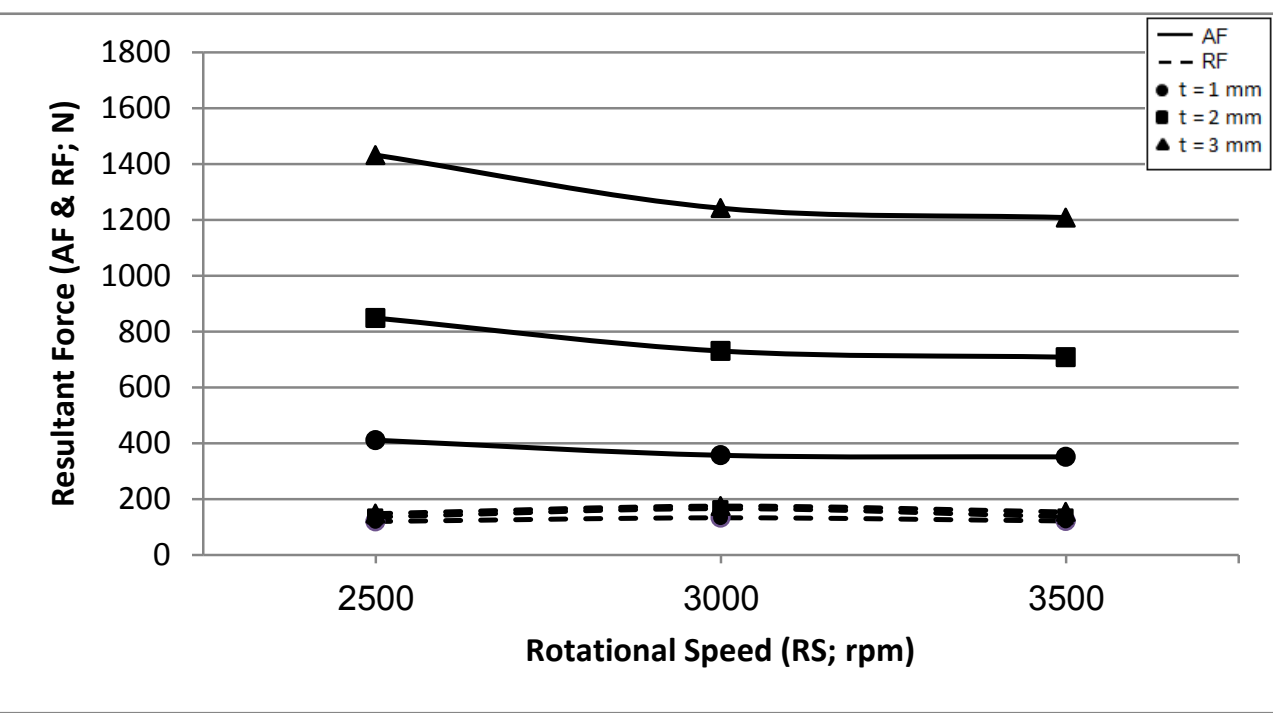

Fig. 7. Effect of rotational speed on the resultant force

The effect of the tool operating parameters on the resultant whole diameter errors was also studied. Generally, the values of the RE are very small compared to the DE. According to ISO 286-2 grade E13 for nominal hole size 6 12 $\mathrm{mm}$ [16], all the obtained measured DE and RE values are within the permissible standard values, so the effect of the operating parameters are neglectable with respect to the DE and RE. For example, Fig. 8 shows the effect of $d$ on the DE and RE at different $t$ values.

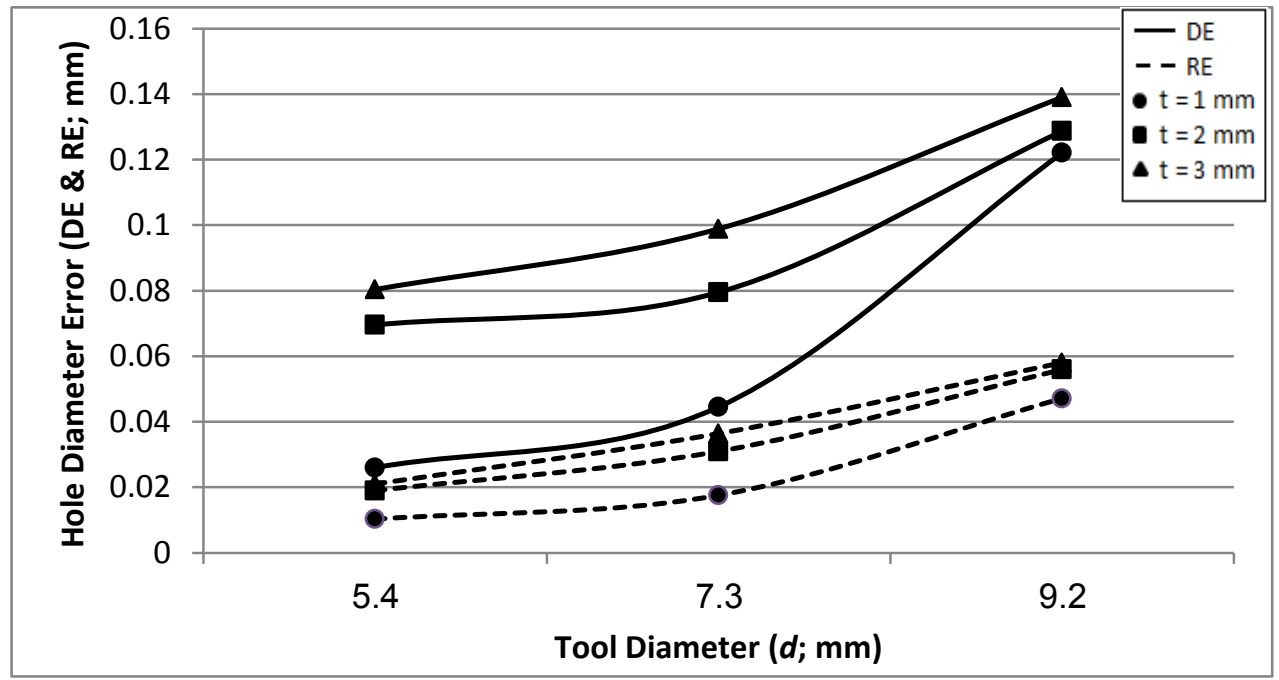

Fig. 8. Effect of tool diameter on the hole diameter error 
From the above discussion, the tool operating parameters have significant effects on the AF and BL. To study the effect of the parameters on both the AF and BL together analytically, Fuzzy Logic technique and ANOVA are used.

\section{FUZZY LOGIC TECHNIQUE AND ANALYSIS OF VARIANCE}

To construct the inference model of the multiple performance characteristic index (MPCI) correlated with the resultant $\mathrm{AF}$ and $\mathrm{BL}$, MATLAB software has been used. The inputs are the AF and BL means normalized values for each experiment, and the output is the MPCI.
Since the experimental design is orthogonal, so it is possible to separate out the effect of each process parameter at different levels [17]. For example, the MPCI mean for the $d$ parameter at levels 1,2 and 3 can be calculated by averaging the MPCI for experiments 1-6, 712, and 13-18, respectively as illustrated in Table 2, so the mean of the MPCI for each level of the other process parameters can be computed in a similar manner. Then the results are summarized in a table called the response table. Table 3, shows the resultant response table at $t=1$, 2 , and $3 \mathrm{~mm}$.

Table 3. MPCI mean response table

\begin{tabular}{|c|c|c|c|c|c|c|c|c|c|}
\hline \multirow[b]{3}{*}{$\begin{array}{c}\text { Process } \\
\text { Parameter }\end{array}$} & \multirow[b]{3}{*}{ Level 1} & \multicolumn{8}{|c|}{ MPCI Mean } \\
\hline & & \multicolumn{2}{|c|}{$t=1 \mathrm{~mm}$} & \multicolumn{2}{|r|}{$t=2 \mathrm{~mm}$} & \multicolumn{3}{|c|}{$t=3 \mathrm{~mm}$} & \multirow[b]{2}{*}{ Level 3} \\
\hline & & Level 2 & Level 3 & Level 1 & Level 2 & Level 3 & Level 1 & Level 2 & \\
\hline$d$ & 0.258 & 0.537 & 0.654 & 0.331 & 0.562 & 0.621 & 0.369 & 0.544 & 0.688 \\
\hline$\beta$ & 0.528 & 0.488 & 0.434 & 0.561 & 0.516 & 0.437 & 0.609 & 0.532 & 0.461 \\
\hline FCAR & 0.491 & 0.485 & 0.473 & 0.521 & 0.498 & 0.495 & 0.586 & 0.584 & 0.431 \\
\hline FR & 0.541 & 0.480 & 0.428 & 0.590 & 0.466 & 0.458 & 0.615 & 0.508 & 0.478 \\
\hline $\mathrm{RS}$ & 0.394 & 0.490 & 0.565 & 0.472 & 0.506 & 0.536 & 0.468 & 0.554 & 0.579 \\
\hline
\end{tabular}

However, the relative importance amongst the process parameters for the performance characteristic still needs to be known, so that the optimal combinations of the process parameter levels can be determined more accurately. The statistical analysis of variance (ANOVA) is used to investigate which process parameters significantly affect the performance characteristics. This is accomplished by separating the total variability of the multi performance characteristics indexes, which is measured by the sum of the squared deviations from the total mean of the MPCI, into contributions by each of the process parameter and the error. The sum of the squared deviations due to each process parameter $k\left(\mathrm{SS}_{\mathrm{k}}\right)$ can be calculated according to the following Equation (3) [18].

$S S_{k}=m \sum_{i=1}^{n}\left(\text { MPCI } \operatorname{Mean}_{i}-\eta_{m}\right)^{2}$

where $m$ is the number of each level appearance for each factor in the orthogonal array, and $n$ is the level number for each parameter. The percentage contribution by each of the process parameter in the total sum of the squared deviations can be used to evaluate the importance of the process parameter change on the performance characteristics.

Table 4, shows the results of ANOVA. It indicates that the tool diameter is the most significant process parameter in affecting the AF and BL together.

From the experimental and analytical analysis, the optimal results obtained at $\beta=30^{\circ} \sim 45^{\circ}$, FCAR $=50 \sim 75$ $\%, \mathrm{FR}=60 \mathrm{~mm} / \mathrm{min}$, and $\mathrm{RS}=2500 \sim 3500 \mathrm{rpm}$, regardless the workpiece thickness and the tool diameter. Due to the achieved results at the obtained optimal ranges of $\beta, \mathrm{FCAR}, \mathrm{FR}$, and $\mathrm{RS}$ are very close to each other within $5 \sim 10 \%$, and these parameters are not significant, then the optimal process parameters combination will be: $\beta=30^{\circ}, \mathrm{FCAR}=50 \%, \mathrm{FR}=60 \mathrm{~mm} / \mathrm{min}$, and $\mathrm{RS}=3500$ $\mathrm{rpm}$ at any work piece thickness or tool diameter, for the proposed experimental levels.

\begin{tabular}{|c|c|c|c|c|c|c|}
\hline \multirow[b]{2}{*}{$\begin{array}{c}\text { Process } \\
\text { Parameters }\end{array}$} & \multicolumn{2}{|c|}{$t=1 \mathrm{~mm}$} & \multicolumn{2}{|c|}{$t=2 \mathrm{~mm}$} & \multicolumn{2}{|r|}{$t=3 \mathrm{~mm}$} \\
\hline & Sum of square & Contribution (\%) & $\begin{array}{l}\text { Sum of } \\
\text { square }\end{array}$ & Contribution (\%) & $\begin{array}{l}\text { Sum of } \\
\text { square }\end{array}$ & Contribution (\%) \\
\hline$d$ & 0.495 & 72.328 & 0.281 & 59.661 & 0.306 & 48.374 \\
\hline$\beta$ & 0.027 & 3.951 & 0.047 & 9.929 & 0.066 & 10.374 \\
\hline FCAR & 0.001 & 0.152 & 0.002 & 0.525 & 0.095 & 15.068 \\
\hline FR & 0.038 & 5.555 & 0.066 & 13.975 & 0.062 & 9.877 \\
\hline $\mathrm{RS}$ & 0.088 & 12.873 & 0.012 & 2.591 & 0.041 & 6.429 \\
\hline Error & 0.035 & 5.142 & 0.063 & 13.320 & 0.062 & 9.880 \\
\hline Total & 0.685 & 100.00 & 0.470 & 100.00 & 0.632 & 100.00 \\
\hline
\end{tabular}

\section{CONCLUSIONS}

This paper has studied the effect of changing the thermal friction drilling process parameters such as the tool geometry, feed rate, and rotational speed, on the resultant bushing length, axial force, radial force, hole diameter dimensional error, and roundness error, while drilling AISI 304 stainless steel sheets with different thickness by uncoated tungsten carbide tools. Experimental results show that by increasing the work piece thickness the resultant measured parameters increased. Also the tool diameter is the most significant parameter affecting the $\mathrm{AF}$ and $\mathrm{BL}$ together comparing to 
the other considered parameters. This study can be applied on the friction drilling of various malleable metals including mild steel, stainless steel, copper, brass, and aluminum to generate precision holes. Also different machining conditions can be considered, so as to build a computer aided process planning expert system of thermal friction drilling process with the goal of automation.

\section{ACKNOWLEDGEMENTS}

The first author would like to acknowledge Flowdrill Company in Netherlands for offering the needed tools. Also she would like to acknowledge Shoman Company in Egypt for their great help and support in offering the facilities and tools needed to conduct this work.

\section{REFERENCES}

[1.] Sobotová L., Kmec J. and Bičejová L., "Thermal Drilling - New Progressive Technology," Annals of Faculty Engineering, Hunedoar-International Journal of Engineering, pp. 371-373, 2011.

[2.] Sobotová L., "The Creation of Joinings by Thermal Drilling Method," Ministry of Education of the Slovak Republic, pp. 80-82, 2012.

[3.] Wu C.D., Fang T.H., and Kuo C.H., "Atomistic simulation of nanodrilling mechanics and mechanism on $\mathrm{Cu}$ substrates," Applied Physics A, Materials Science and Processing, (C) SpringerVerlag Berlin Heidelberg, DOI 10.1007/s00339014-8732-5, August 2014.

[4.] Prabhu T. and Arulmurugu A., "Experimental and Analysis of Friction Drilling on Aluminum and Copper," International Journal of Mechanical Engineering and Technology (IJMET), pp. 123132, Volume 5, Issue 5, ISSN 0976 - 6359 (Online), May 2014.

[5.] http://www.flowdrill.com/.

[6.] Streppel A.H. and Kals H.J.J., "Flowdrilling: a Preliminary Analysis of a New Bush-Making Operation," Annals of the CIRP, pp. 167-171, Vol. 32/1, 1983.

[7.] $\mathrm{Qu} \mathrm{J.} \mathrm{and} \mathrm{Blau} \mathrm{P.J.,} \mathrm{"A} \mathrm{New} \mathrm{Model} \mathrm{to} \mathrm{Calculate}$ Friction Coefficients and Shear Stresses in Thermal Drilling," Journal of Manufacturing Science and Engineering, pp. 014502/1-014502/4, Vol. 130, February 2008.

[8.] Fernández A., Lopez de Lacalle L.N. and Lamikiz A., "Friction Drilling of Stainless Steels Pipes," International Conference on Advances in Materials and Processing Technologies, pp. 1187-1192, 2010.

[9.] Miller S.F., "Experimental Analysis and Numerical Modeling of the Friction Drilling Process," PHD thesis (Mechanical Engineering), University of Michigan, 2006.

[10.] Miller S.F., Blau P.J. and Shih A.J., "Microstructural Alterations Associated With Friction Drilling of Steel, Aluminum, and Titanium," Journal of Materials Engineering and Performance, Vol. 14(5, pp. 647-653), October 2005.

[11.] Krasauskas P., "Experimental and Statistical Investigation of Thermo-Mechanical Friction
Drilling Process," Mechanika, Vol. 17(6), pp. 681686, 2011.

[12.] Ozek C. and Demir Z., "Investigate the Friction Drilling of Aluminum Alloys According to the Thermal Conductivity," TEM Journal, Volume 2, Number 1, 2013.

[13.] El-Bahloul S.A, El-Shourbagy H.E, and El-Midany T.T, "Optimization of Thermal Friction Drilling Process Based on Taguchi Method and Fuzzy Logic Technique," International Journal of Science and Engineering Applications, Volume 4, Issue 2, ISSN-2319-7560 (Online), 2015.

[14.] Tsai P., Gilmour, S.G., and Mead R., "Some New Three-Level Orthogonal Main Effects Plans Robust to Model Uncertainty", Statistica Sinica 14(2004), PP.1075-1084, 2004.

[15.] Oberg E., Jones F.,, Horton H., Ryffel H., McCauley C., "Machinery's Handbook $29^{\text {th }}$ Edition-Toolbox", ISBN: 9780831129002, January 2012, http://www.roymech.co.uk/ Useful_Tables/ Screws/Thread_Calcs.html.

[16.] http://www.iso.org/iso/home/search.htm?qt=iso+2 86,http://www.cobanengineering.com/Tolerances/I SOHoleTolerances3mmTo400mm.asp.

[17.] [17] Hsiang, S., and Lin Y., "Optimization of the extrusion process for Magnesium alloy sheets using the fuzzy based Taguchi method", the Arabian journal for science and engineering, volume 34, number 1c, 2009.

[18.] Athreya Srinivas and Venkatesh Y.D., "Application of Taguchi Method for Optimization of Process Parameters in Improving the Surface Roughness of Lathe Facing Operation", International Refereed Journal of Engineering and Science (IRJES), ISSN (Online) 2319-183X, (Print) 2319-1821, Volume 1, Issue 3, PP.13-19, November 2012. 